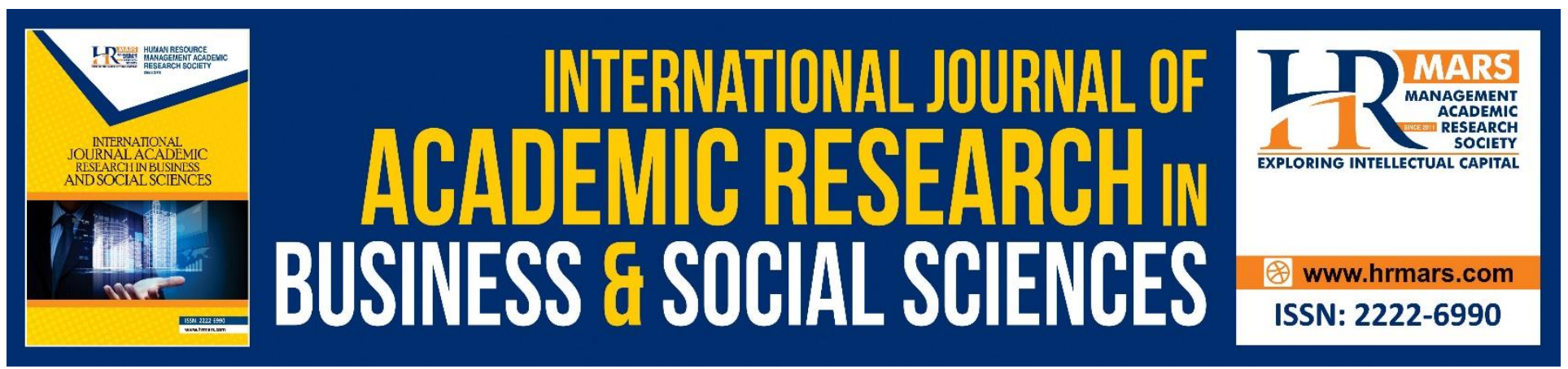

\title{
Understanding the Digital Capabilities of Rural Communities in Low Literacy Rate Areas in Malaysia towards Digital Society
}

Samsul Farid Samsuddin, Nor Aini Mohamed, Jusang Bolong

To Link this Article: http://dx.doi.org/10.6007/IJARBSS/v11-i15/10644 DOI:10.6007/IJARBSS/v11-i15/10644

Received: 10 May 2021, Revised: 13 June 2021, Accepted: 28 June 2021

Published Online: 24 July 2021

In-Text Citation: (Samsuddin et al., 2021)

To Cite this Article: Samsuddin, S. F., Mohamed, N. A., \& Bolong, J. (2021). Understanding the Digital Capabilities of Rural Communities in Low Literacy Rate Areas in Malaysia towards Digital Society. International Journal of Academic Research in Business and Social Sciences, 11(15), 174-184.

Copyright: (c) 2021 The Author(s)

Published by Human Resource Management Academic Research Society (www.hrmars.com)

This article is published under the Creative Commons Attribution (CC BY 4.0) license. Anyone may reproduce, distribute, translate and create derivative works of this article (for both commercial and non-commercial purposes), subject to full attribution to the original publication and authors. The full terms of this license may be seen

at: http://creativecommons.org/licences/by/4.0/legalcode

Special Issue: Empowering Youth and Community Wellbeing for Sustainable Development, 2021, Pg. 174 - 184

http://hrmars.com/index.php/pages/detail/IJARBSS

JOURNAL HOMEPAGE

Full Terms \& Conditions of access and use can be found at

http://hrmars.com/index.php/pages/detail/publication-ethics 


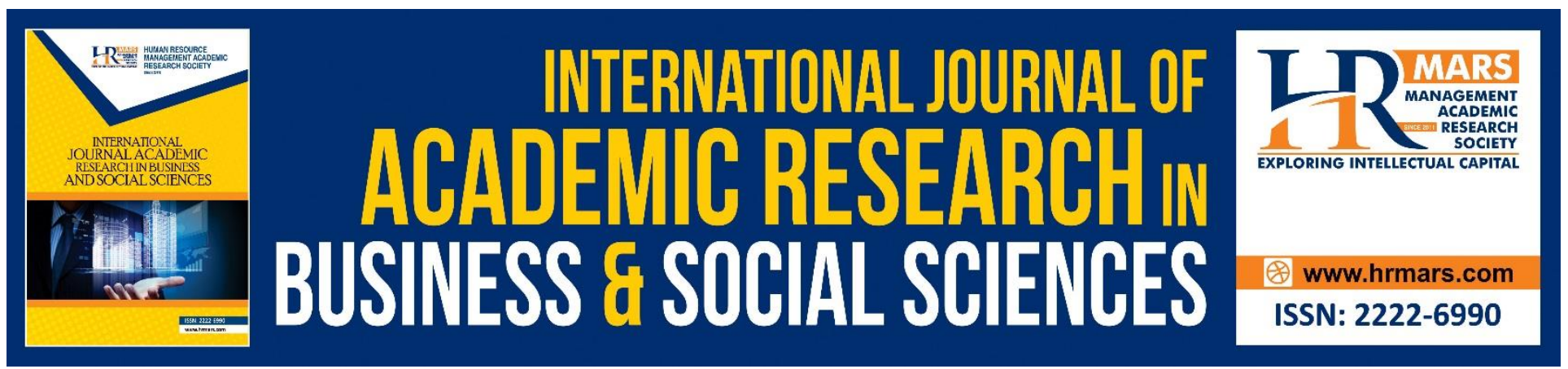

\title{
Understanding the Digital Capabilities of Rural Communities in Low Literacy Rate Areas in Malaysia towards Digital Society
}

\section{Samsul Farid Samsuddin}

Department of Library \& Information Science, Faculty of Computer Science and Information Technology, University of Malaya, 50603 Kuala Lumpur, Wilayah Persekutuan Kuala Lumpur, Malaysia.

Email: samsulfarid@gmail.com

\begin{abstract}
Nor Aini Mohamed
Institute for Social Science Studies, Universiti Putra Malaysia, 43400 Serdang, Selangor, MALAYSIA. Email:nm_aini@upm.edu.my

\section{Jusang Bolong}

Faculty of Modern Language and Communication, Universiti Putra Malaysia, 43400 Serdang,

Selangor, Malaysia.

Email: jusang@upm.edu.my
\end{abstract}

\begin{abstract}
Despite several activities been focusing on urban areas, rural areas are no exception in being a digital society. Since the year 2000, various initiatives such as rural libraries establishment and Universal Service Provision (USP) programs tend to narrow down the digital divide between rural and urban areas in Malaysia. However, few empirical studies have been carried out on information access and usage of digital technologies among rural communities in Malaysia. The purpose of this paper is to investigate the digital capabilities of rural communities in low literacy rate areas in Malaysia towards a digital society. This study is a quantitative method and descriptive kind of study using questionnaires as an instrument to collect the data. Multi-stage clusters and simple random sampling were employed and 400 respondents were selected. Analysis performed confirms that rural communities in Malaysia, are digitally connected and informed society (Digital Society). Smartphones and the Internet were the highest types of ICT tools used by the rural communities in the study. The result did reflect on the ownership of their ICT tools, which most of the rural communities afford to have their own smartphones regardless of the level of age. A better understanding of digital capabilities towards information access and usage of digital technologies among rural communities could produce a better understanding of the adoption and usage of digital technologies. The findings are also expected to provide useful inputs in ensuring that the advancements in communications
\end{abstract}


infrastructure and services contribute to the inclusion and participation of all segments of the population in the realization of a Digital Society. Meanwhile, able to understand the human and social factors, which affect and contribute to the adoption and usage of digital technologies and services.

Keywords: Digital Society, Digital Capabilities, Information Access, Usage of Digital Technologies, Rural Community, Community Development, Rural Development.

\section{Introduction}

Information and communication technology (ICT) has an important role in terms of development in rural areas in Malaysia. In addition, ICT also serves as a mechanism in bridging the digital divide that exists between urban and rural areas (Bashir et al., 2011). Clearly, the increase in ICT technology has shown impressive transformation results in the socio-economic environment of the country. This strategy aims to ensure rapid development in rural areas by improving the living conditions of rural communities, in line with the National "Sustainable development Goal" (SDGs). SDGs is a world development program that aims to prosper the world community and preserve nature with 17 key factors as well as the achievement of 169 targets that have been determined in the agreed time. Among the government's initiatives to ensure Malaysia achieves the status of a developed country in the future, several facilities and services have been introduced to rural communities to strengthen rural infrastructure such as wireless villages, broadband community libraries, and rural internet centers (Shaffril et al., 2010; Badsar et al., 2011; Samah et al., 2011).

There are various definitions of digital society used based on past studies such as, "using technology competently; interpret and understand the credibility of digital content; creating, researching and communicating with appropriate tools; critically thinking on ethical issues; security and safety; and self-responsible while online" (Isman \& Gungoren, 2014). However, for this current study, the general definition of digital society used is a society that uses a variety of the latest ICT technology tool or equipment for various purposes in carrying out daily activities especially in obtaining digital content.

The results of research conducted by the Malaysian Communications and Multimedia Commission (MCMC, 2019) show that the level of household Internet usage for urban communities is 70.0 percent, while among rural communities only 30.0 percent in 2018. It is found 2.8 percent a decrease when compared to a study conducted in 2016, with the ratio of strata Internet users being 2.3 urban users to 1.0 rural users. The results are in line with a survey conducted in 2002 among the villagers with excellent village status (villages categorized as advanced) by Sharifah (2003) showed that the ownership of ICT tools among the rural population is generally low. Of the 1,652 households surveyed, only 18 percent had their home computers, and only 6.7 percent had Internet connections, leading to the assumption that the level of digital use among the rural population in Malaysia was low. Meanwhile, in 2012, the rate of mobile phone users in rural areas recorded 31.2 percent, an increase of 4.9 percent compared to 2007. Besides, the number of male mobile phone users exceeded the total number of female users by recording 56.5 percent compared to 43.5 percent (MCMC, 2019). The percentage of individuals in Malaysia aged between 15 to 34 years who use the Internet is 52.8 percent. Meanwhile, 97.9 percent of individuals use mobile phones in 2018 compared to 97.7 percent in 2017 (DOSM, 2019).

In meeting personal needs, especially the youth, the conservative way of obtaining knowledge has been combined with current technologies such as the Internet (Kamarudin et al., 2019). The 
Malaysian scenario also shows that among the major users of the internet are the youth (IPPBM, 2013; Hassan et al., 2014). The Malaysian Institute for Research in Youth Development (IPPBM) (2013) for example has shown that most youths use the internet 4-5 times a week and some of them spend up to 28 hours a week using the internet. Meanwhile, findings by Lee et al (2012) suggest that youth are active users of social media and blogs. Recognizing this fact, the government has initiated several initiatives such as the Community Broadband Library, the Wireless Village, the 1 Malaysia Netbook Program, and the 1 Malaysian Internet Center which is expected to encourage digital usage among communities, especially those who are youth and thus to bridge the digital divide that still exists between urban and rural people (Kamarudin et al., 2019; Samsuddin et al., 2015). With the development of technology and the current age of sophistication, the interest in children's learning can still be nurtured even digitally.

\section{Background of the Study}

Despite several activities been focusing on urban areas, rural areas are no exception in being a digital society. Since the year 2000, various initiatives such as rural libraries establishment and Universal Service Provision (USP) programs tend to narrow down the digital divide between rural and urban areas in Malaysia. However, few empirical studies have been carried out on information access and usage of digital technologies among rural communities in Malaysia currently, especially in terms of obtaining digital content.

The existence of electronic medium (non-printed medium) and social media medium has an impact on information sharing and dissemination of current information. Printed medium is a medium that has text, pictures, that appears on paper or books or whatever medium you can touch and hold. Whereas electronic mediums such as books and other reading materials are displayed in various forms of information in electronic media (television, radio, video players, computers, and other electronic devices). The social media medium is also known as the new medium is a digital source of information, which involves a combination of various forms of media (audio, image, message, text, video) and its dual-functioning of communication also called applications. Most of the applications associated with this social media medium require internet access to use. Understanding social media is a way of interacting with people where they can create, share, and exchange information and ideas within communities and virtual networks. The use and access of reading materials from these electronic and social media mediums however requires the involvement of other devices such as nonsmartphones, smartphones, tablets, iPad, laptops, desktops. Also, the concept of the electronic medium and social media medium involves technical aspects (such as a hard drive as digital storage media) and transmission aspects (such as computer networks for the dissemination of digital information).

We often think and assume that rural people in Malaysian do not acquire and capable of current technology facilities, but this assumption is completely false. Rural Malaysians in this era acquired more than they did centuries ago through smartphone and Internet subscriptions. Albeit that, the Malaysian Communications and Multimedia Commission (MCMC, 2019) has revealed that the type of online content shared mostly was educational content (71.3\%). Efforts to encourage youth especially those in rural areas to read digital content are important, as they are often associated with low socioeconomic levels community. Previous studies such as Landow (1992); Lanham (1993) have shown that reading digital materials can help rural youth improve knowledge, and skills which in turn 
helps them to diversify the economic resources as well as expanding social networks. However, this is not an easy task, the main challenge facing the government today is that many youths are less interested in reading digital materials and most of them use the Internet for social, entertainment, and enjoyment purposes (The Star, 2009). Despite such a scenario, however, it can be overcome if the understanding of the factors contributing to digital content is obtained.

Digital capabilities within the meaning of this study are capabilities or ownership in terms of ICT equipment owned, including capabilities and abilities in digital use through existing experience and skills. Where this capability and ability are one of the important factors in facing the challenges of modern life. If this capability is not possessed or acquired by society it will be left behind by the rapid current of modernization. In particular, it is demanding in the new norms of life after the presence of the covid-19 pandemic. The needs not only in terms of education but involve the entire current socioeconomics status. By knowing and understanding the current capabilities, it can help to meet specific needs and facilitate the planning of programs such as interventions from various related parties.

Although there is a need for such studies, however, there are not many studies and it is crucial to first understand the information access and usage of digital technologies among specific groups such as rural youth and rural communities towards a digital society. To address the needs, it is a must to conduct a study where the main objective is to investigate the digital capabilities of rural communities in Malaysia towards a digital society. These research questions can be a guide throughout the research on capabilities among rural communities with low literacy rate areas in Malaysia:

a. What is the current status of ICT ownership among rural communities?

b. What is the level of ICT experience and ICT skills possessed on selected ICT tools?

c. What are the types of ICT tools preferred to use in obtaining digital content?

\section{Methodology}

This study is a quantitative method and descriptive kind of study using questionnaires as an instrument to collect the data. Due to limited budget and time-consuming, only selected districts were considered for this study which represents the population of the rural community in low literacy rate areas in Malaysia. Multi-stage clusters and simple random sampling were employed and 400 respondents were selected. Respondents between 15 to 40 years of age from Pendang (Kedah), Jeli (Kelantan), Betong (Sarawak), and Ranau (Sabah) districts have been identified through the random stages (Table 1). However, this limitation and assumption could be overcome by conducting a future study that involves rural communities that are not considered low on literacy rate areas also among communities in suburban areas. 
INTERNATIONAL JOURNAL OF ACADEMIC RESEARCH IN BUSINESS AND SOCIAL SCIENCES

Vol. 11, No. 15, Empowering Youth and Community Wellbeing for Sustainable Development, 2021, E-ISSN: 2222-6990 @ 2020 HRMARS

Table 1. Multi-stage and simple random sampling

\begin{tabular}{ccc}
\hline $\begin{array}{c}\text { Four (4) States rated } \\
\text { low literacy in Malaysia }\end{array}$ & $\begin{array}{c}\text { Selected districts } \\
\text { (randomly choose) }\end{array}$ & $\begin{array}{c}\text { Number of } \\
\text { respondents } \\
\text { approached }\end{array}$ \\
\hline Kedah & Pendang & 100 \\
Kelantan & Jeli & 100 \\
Sarawak & Betong & 100 \\
Sabah & Ranau & 100 \\
\hline & & Total \\
\hline
\end{tabular}

\section{Findings}

Capabilities towards digital society among rural communities been measured in this study were based on ICT tools ownership, experience, and skills in handling ICT tools. Besides that, types of ICT tools preferred in obtaining digital contents were also identified.

\section{Readiness in Terms of ICT Ownership, ICT Experience, and ICT Skills}

Eight (8) ICT tools were listed as common ICT tools owned by normal household are smartphone, Internet/ Wi-Fi/ Broadband, non-smartphone, laptop/ notebook, computer/ desktop, tablet/ iPad, PlayStation/ PSP, iPod/ mp3 for current study. Out of 400 respondents involved in this study, the smartphone has recorded as higher percentage owned by rural communities with 88.3 percent. While second ranks stated at 59.8 percent that rural communities have their own Internet/ Broadband connection. Follows by non-smartphone (38.8\%), laptop/ notebook (33.3\%) and other 4 ICT tools rated 10 percent and below are computer/ desktop (10\%), tablet/ iPad (9.8\%), PlayStation/ PSP $(3.8 \%)$ and iPod/ mp3 (1\%) (Figure 1). This finding shows that the respondents mostly owned smartphones and the Internet. These ICT tools were widely used and considered as complimentary needs to most people as communication tools nowadays. Inline with MCMC (2019) survey, internet users used to communicate by text $(96.5 \%)$ and social networking platforms $(85.6 \%)$ during their online activities. Although non-smartphone also functioning for communication purposes, the ability and features were lack than smartphones. The average price for each smartphone was affordable and has various choices and rates according to user capabilities. Meanwhile, between computer/ desktop and laptop/ notebook, rural communities preferred to have laptop/ notebook due to their mobile ability. Compare to tablets/ iPad, the size might not suitable for bigger households, and the price slightly similar to other computers or laptops. However, all the ICT tools owned by rural communities were suitable for digital usage practices. They can download or read all digital content available throughout the networks without barriers. In addition, within the online reading environment, they can easily adopt various navigational strategies especially in terms of information searching (Azmuddin et al., 2018). 


\section{Figure 1. ICT Ownership}

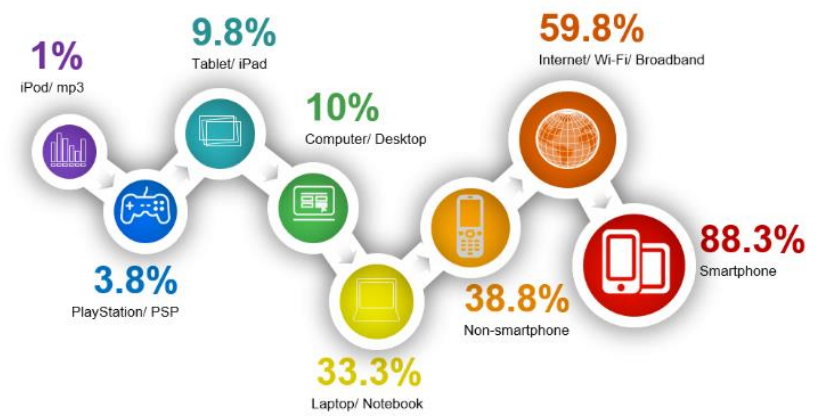

According to figure 2, ICT experience and skills were identified based on the ICT tools listed. The measurement for ICT experience was based on, have used the ICT tools for at least 1 year, and whether they know to at least operate and applied the ICT tools into reasonable meaning measuring the ICT skills. Most of the respondents have experienced more than 1 year of use and know very well how to use a smartphone, Internet, non-smartphone, computer, and laptop. Based on these experiences and skills of ICT tools among rural communities have shown that positive capabilities and readiness level towards a digital society. Most of them are familiar with the ICT tools which will increase their usage towards obtaining digital content. Even if they did not own the ICT tools by themselves, according to their experience and skill, they still can use their peers or ICT services and facilities provided within their local community. The digital usage practice seems not a big problem for rural communities by using these ICT tools.

Figure 2. ICT Experience vs ICT Skill

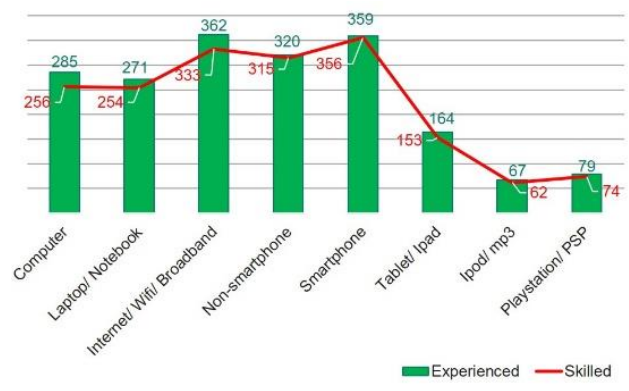

Types of ICT Tools Preferred

Table 2. Types of ICT tools preferred to use for digital content

\begin{tabular}{lll}
\hline ICT tools preferred to use & Frequency & Percentage \\
\hline Internet & 340 & 85.0 \\
Smartphone & 339 & 84.8 \\
Laptop & 93 & 23.3 \\
Computer/ Desktop & 48 & 12.0 \\
Ipad/ Tablet & 43 & 10.8 \\
None & 40 & 10 \\
\hline
\end{tabular}

In this section, the non-smartphone, Playstation/ PSP, and iPod/ $\mathrm{mp3}$ are not included due to its functions limited to communication and leisure only. Findings in Table 2 show that most of the respondents preferred the Internet and smartphone as their ICT tools to use for digital content. Internet and smartphones are an inseparable combination. By owning a smartphone it is usually 
equipped with an internet network, either by using a prepaid or post-paid line. The result was significant with a previous study done by Samsuddin et al. (2020) that rural communities spend most of their time surfing the internet. The potential use of this smartphone and internet has shown that it is a choice of many users including the rural community. Similar findings by Abdul Karim and Hassan (2007) have found that rural communities choose ICT tools based on ease of access and mobility aspects. Also, the prices of smartphones and the internet nowadays much lower and are in line with the capabilities of rural people, compared to other devices such as laptops and iPads / Tablets. Efforts from the government in terms of ICT tools provisions and control of price with telemarketer collaboration were giving a positive impact. However, there is a discrepancy or gap in terms of research findings between the Internet as one of the ICT tools preferred $(85.0 \%)$ and Internet ownership (59.8\%) (figure 1). These findings indicate that although the Internet is the main choice in ICT tools to use for digital content, but there are only more than half of the respondents who own or subscribe to Internet. This is because there are several Internet access facilities provided by the government and local authorities in some rural areas. Among the Internet access facilities provided are within the rural library facilities, Community Internet Center, and open areas that are usually the focus of the villagers, such as by the community hall or youth recreation area known as wireless village facilities (Samsuddin et al., 2020). Therefore, for some rural communities they prefer to make full use of the facilities provided to them without any additional charge to access the internet.

\section{Discussion}

Ownership of smartphones and the Internet in terms of subscriptions found that there is very little disparity in advance of urban and rural communities. This is because, in terms of awareness, the importance of owning this technology is more to the main needs. By understanding the function and role of ICT equipment it is also helpful in increasing the number of ownership among the rural population. In this new norm, the current needs of adolescents in education require them to have at least equipment such as computers or smartphones that have an internet connection for teaching and learning at home also known as PdPR (Teaching and Learning at Home). Based on the findings of the study, the capability in terms of ownership of this ICT equipment is positive, where almost 90 percent of the rural communities involved in this study own a smartphone and more than 50 percent have an Internet connection. While for individuals who do not have access to the Internet can use other alternatives such as Internet facilities provided in selected areas such as telecenters, Community Internet Center known as Pusat Internet Komuniti (PIK), rural library or paid Internet center. Otherwise, the authorities such as village leaders or local elected representatives can create a temporary place that provides Internet access facilities to enable the financially disadvantaged to access the Internet at certain times.

In terms of the ICT tools usage, the average rural community (80 percent) have been and are skilled in using ICT tools such as Smartphones and the Internet. This can be seen in the effect of the application of ICT subjects in the school learning syllabus at an early stage and the basic criteria in the employment conditions for most government and private sectors in Malaysia. Therefore, mastery of the use of ICT tools should not be a concern though they belong to underserved areas, uniformity in terms of learning approach indirectly bridges the gap between these two urban and rural areas. This successful government action in the field of education can also help rural communities continue their daily lives using ICT tools in the context of lifelong learning for the socio-economic development of individuals and the local area. Whereby nowadays, online businesses are more promising good 
returns through almost no start-up costs such as promotional and advertising costs. Transparency and convenience in terms of anyone can do with minimal knowledge, can help rural communities venture into this industry.

By knowing the real state of capabilities and abilities of specific communities such as rural communities on the ICT equipment they own, it can help relevant parties to formulate local development strategies through the use of this technology as a whole such as Mandated Public Service Announcements and interventions programs via mobile applications such as MySejahtera. MySejahtera is an application developed by the Government of Malaysia to assist in monitoring COVID-19 outbreaks in the country by empowering users to assess their health risk against COVID19. This application also provides the Ministry of Health $(\mathrm{MOH})$ with the necessary information to plan for early and effective countermeasures.

By providing ICT infrastructure in rural areas such as Internet substation and 'telecenters', it just not only reduce the digital divide, it can also provide an ICT advantage to the rural poor. In line with this statement, Kelles-Viitanen (2005) emphasizes the role of ICT which has proven to provide opportunities in the aspects of education, health in terms of services, and promote democracy based on good governance which is a catalyst in the task of poverty eradication. The World Bank Group (2012) reported that ICT can be used effectively to increase business productivity, enhance accountability, accelerating economic growth, and also overcoming the problem of poverty in any community. Digital Inclusion such research is aimed at gap areas related to factors that impede equality of access and challenge the paradigm of ensuring that no one is left behind or is deprived of digital connectivity and its benefits.

This study is important because studies related to digital capabilities and digital society among rural communities have not yet been fully explored in Malaysia. This will further enhance their socioeconomic aspects. Furthermore, the findings of this study are expected to drive the transformation of the socio-economic development of rural communities especially rural youth in Malaysia in line with the intention of the Malaysian government to transform youth groups into knowledgeable, selfreliant, and visionary groups. Most importantly, such studies can assist IPBBM in understanding rural youth while also assisting IPPBM in providing a complete database to support the planning and implementation of youth development programs.

\section{Conclusion}

In conclusion, the rural community is ready and has practiced digital usage, though not entirely. From the aspects of ownership, experience, and skills in the use of ICT tools and equipment, the rural community is positive towards digital society in the future. A better understanding of digital capabilities towards information access and digital usage among rural communities could produce better information on the service provision towards the establishment of rural areas and other rural development programs in low literacy rate areas in Malaysia. The findings are also expected to provide useful inputs to the MCMC in constructing effective strategies to cultivate holly digital usage among reluctant users in rural areas. Meanwhile, the findings able to demonstrate behavior changes in rural communities in terms of information-seeking behavior towards lifelong learning and sustainable life through digital practices. 


\section{References}

Abdul Karim, N. S., \& Hasan, A. (2007). Reading habits and attitude in the digital age: analysis of gender and academic program differences in Malaysia. The Electronic Library, 25(3), 285-298.

Azmuddin, R. A., Fariza, N. M. N., \& Hamat, A. (2018). Using iREAD in understanding online reading strategies applied by science and technology students. International Journal of Web-Based Learning and Teaching Technologies, 13(3), 18-32.

Badsar, M., Samah, B. A., Hassan, M. A., Nizam, O., \& Shaffril, H. A. M. (2011). Predictor Factors of Telecentres Outcome from the Users Perspectives in Rural Communities. American Journal of Applied Science, 8(6), 617-627.

Hassan, M. S., Osman, M. N., Ramli, N. S., \& Shaffril, H. A. M. (2014). Mapping the patterns and problems related to internet usage among university students in Malaysia: some preliminary results. International Education Studies.

Isman, A., \& Canan Gungoren, O. (2014). Digital citizenship. The Turkish Online Journal of Educational Technology, 13(1)73-77.

Kamarudin, S., Omar, S. Z., Bolong, J., Osman, M. N., \& Mahamed, M. (2019). ICT Development of Community in Rural Areas. International Journal of Academic Research in Business and Social Sciences, 9(9), 118-126.

Kelles-Viitanen, A. (2005). New Challenges and Opportunities for Rural Development. IFAD Workshop in Rome. [Online]. Retrieved from http: /www. ifad. org/innovation/presentations/newopp. pdf.

Landow, G. (1992). Hypertext: The Convergence of Technology and Contemporary Critical Theory. Baltimore, MD: Johns Hopkins University Press.

Lanham, R. (1993), The Electronic Word: Technology, Democracy, and the Arts. Chicago, IL: University of Chicago Press.

Lee, J., Paik, W., \& Joo, S. (2012). Information resource selection of undergraduate students in academic search tasks. Information Research, 17(1) paper 511.

Malaysian Communications and Multimedia Commission (MCMC) (2019). Internet Users Survey 2018: Infographic. Internet Users Survey. Retrieved from https://www.mcmc.gov.my/en/resources/statistics/internet-users-survey\#.

Sharifah, N. S. S. (2003). Model planning on traditional village in Peninsular Malaysia. Paper presented at Rural Planning Center, Faculty of Alam Bina, UTM. Technology University of Malaysia Publisher, Skudai, Johor.

Samah, B. A., Shaffril, H. A. M., Hassan, M. A., \& D’Silva, J. L. (2011). Can Technology Acceptance Model be Applied on the Rural Setting: The Case of Village Development and Security Committee in Malaysia. Journal of Social Sciences, 7(2): 113-119.

Shaffril, H. A. M., Samah, B. A., Hassan, M. A., \& D'Silva, J. L. (2010). Socio-economic factors that impinge computer usage in administration works among village leaders in Malaysia. Journal of Scientific Research and Essays, 5(23): 3623-3633.

Samsuddin, S. F., Bolong, J., Omar, S. Z., D’Silva, J. L., Sahharon, H., \& Shaffril, H. A. M. (2015). Examining the impact of demographic factors on the attitude of rural communities in Malaysia towards village WiFi services. Asian Social Science, 11(18), 134-143.

Samsuddin, S. F., Omar, S. Z., \& Shaffril, H. A. M. (2018). Youth development in rural library: ICT gratification as mediating effect. Malaysian Journal of Library \& Information Science, 23(2), 111134. 
Samsuddin, S. F., Shaffril, H. A. M., Bolong, J., \& Mohamed, N. A. (2020). Understanding the reading habit and attitudes among the rural community in low literacy rate areas in Malaysia: Rural library perspectives. Library Management, 41(1), 39-52.

The Malaysian Institute for Research in Youth Development (IPPBM) (2013). Youth facts: media literacy. Retrieved from: http://ippbm.gov.my/index.php/component/content/article.html?id=347.

The Star. (2009). Survey: $45 \%$ of Malaysian youth use Internet over other media. Retrieved from: http://biz.thestar.com.my/news/story.asp?file=/2009/4/8/business $/ 3651619 \&$ sec $=$ business.

The World Bank Group. (2012). The World Bank, World Development Indicators Databank, Washington, D.C.: The World Bank Group. 